\title{
Compromised maternal nutritional status in early pregnancy and its relation to the birth size in young rural Indian mothers
}

Devaki Gokhale ${ }^{1 *}$ and Shobha Rao ${ }^{2}$

\begin{abstract}
Background: Low birth weight is highly prevalent in rural India. As a chronic undernutrition problem, poor birth outcomes are closely related to various nutritional factors more prominently the poor maternal anthropometry at conception. The purpose of the study was to identify how compromised maternal nutritional status in early pregnancy affects the birth size of rural Indian mothers.

Methods: It was a prospective observational study on singleton pregnant women $(n=204)$ from 14 villages in Mulshi Taluka of Pune District, Maharashtra, India. Maternal weight (Wt), height ( $\mathrm{Ht})$, body fat percent (BF\%), head circumference $(\mathrm{HC})$, and sitting height $(\mathrm{SHT})$ were measured at early pregnancy $(<13$ weeks of gestation) and infants' weight and length were measured within $24 \mathrm{~h}$ of birth. Groups means were tested using a ' $\mathrm{t}$ ' test while the trend in means was tested using ANOVA.

Results: Mothers were young $(21.46 \pm 2.09 \mathrm{yrs})$, thin $(46.46 \pm 6.1 \mathrm{~kg})$, short $(153.39 \pm 5.79 \mathrm{~cm})$, and poorly nourished $\left(19.74 \pm 2.41 \mathrm{~kg} / \mathrm{m}^{2}\right)$. Mean birth weight was low $(2655 \pm 507 \mathrm{~g})$ and prevalence of LBW and stunting at birth was highest among mothers in the lower tertile of each of the anthropometric indicators. In particular, stunting was significantly higher for mothers in lower tertile compared to higher tertile of Wt (44.6 Vs 64.6\%) and was also true for HC (43.7 Vs 60.6\%). Risk for LBW and stunting at birth was almost similar and was significant $(p<0.01)$ for mothers in the lower tertile of $\mathrm{Wt}, \mathrm{Ht}, \mathrm{BMI}, \mathrm{SHT}, \mathrm{HC}$, and $\mathrm{BF} \%$ as compared to those in the higher tertile of these measurements.

Conclusion: All the anthropometric indicators of current undernutrition at first trimester as well as that in utero reflected by smaller $\mathrm{HC}$, impose risk for LBW and stunting at birth especially among young rural mothers.
\end{abstract}

Keywords: Low birth weight, Stunting, Sitting height, Chronic undernutrition, A young mother

\section{Background}

Low birth weight (LBW) is a major concern worldwide especially in a developing country like India with a prevalence of $30-35 \%$ [1]. Though the causes of LBW are few and known to be prematurity and small for gestational age the consequences are many ranging from

\footnotetext{
* Correspondence: devakijgokhale@gmail.com

'Symbiosis Institute of Health Sciences, Symbiosis International Deemed University, Pune, Maharashtra 412115, India

Full list of author information is available at the end of the article
}

morbidity to mortality. It is a multifactorial phenomenon of public health importance and a measure of the quality of life and survival of the future generation $[2,3]$. The relationship between maternal malnutrition and its effect on birth outcome has been highlighted in several studies [4-7]. Maternal anthropometry is one such avenue wherein several indicators have been studied for their influence on birth outcome [8-11].

In particular, among various maternal anthropometric indicators maternal weight has been mostly explored in

(c) The Author(s). 2021 Open Access This article is licensed under a Creative Commons Attribution 4.0 International License, which permits use, sharing, adaptation, distribution and reproduction in any medium or format, as long as you give appropriate credit to the original author(s) and the source, provide a link to the Creative Commons licence, and indicate if changes were made. The images or other third party material in this article are included in the article's Creative Commons licence, unless indicated otherwise in a credit line to the material. If material is not included in the article's Creative Commons licence and your intended use is not permitted by statutory regulation or exceeds the permitted use, you will need to obtain permission directly from the copyright holder. To view a copy of this licence, visit http://creativecommons.org/licenses/by/4.0/ The Creative Commons Public Domain Dedication waiver (http://creativecommons.org/publicdomain/zero/1.0/) applies to the data made available in this article, unless otherwise stated in a credit line to the data. 
previous studies. For example, rural women from India [12], Sri Lanka [13], and Nepal [14] whose body weight was $<44.6 \mathrm{~kg},<50 \mathrm{~kg}$, and $<45 \mathrm{~kg}$ respectively were shown to be high-risk mothers for delivering low birth weight babies. Though maternal height has not been studied extensively, BMI $\left(\mathrm{kg} / \mathrm{m}^{2}\right)$ has shown a significant influence on the risk of LBW $[12,15,16]$. Besides these indicators, maternal body fat \% though measured by a few researchers [16], have rarely examined as a risk factor for LBW. Apart from the anthropometric measures several demographic variables like maternal age [17], menarcheal age [18], and parity [19] also have been studied with risk of LBW.

Unlike low birth weight, short birth length or stunting at birth has not been studied widely. Most anthropometric indicators studied are reflective of the mother's current nutritional status rather than her past nutritional status and it is necessary to take into consideration the role of her past undernutrition too. For example, height and its components especially leg length/sitting height is known to be an indicator of past malnutrition but is never studied with risk of LBW or stunting at birth. The same is the case with maternal $\mathrm{HC}$ which is known as a surrogate measure of maternal undernourishment inutero [20]. We, therefore, address these issues in the present study to examine how compromised maternal undernutrition in early pregnancy imposes a risk for LBW as well as stunting at birth.

\section{Methods}

\section{Subjects}

The prospective cohort study was conducted across three primary health centers (PHC) in rural areas of Mulshi Taluka, Pune, Maharashtra. These primary health centers covered 14 villages and approximately 5000 beneficiaries. The villages had a well-established network of community workers such as Anganwadi workers and ASHA (Accredited Social Health Activist) workers who were involved in door-to-door registration and tracking of newly married young women and their subsequent pregnancies. These women were referred to the nearest PHC by community health workers and hence tracking them within the first 3 months of gestation for the study in a well-established setup was possible. The sample size was determined considering the prevalence of LBW of $30 \%$, an allowable error of $7 \%$, a level of significance of $5 \%$, and considering loss to follow up of $15 \%$. Though the exact estimate was 196 we enrolled 208. Multiple pregnancies [1], stillbirths [2], and premature [1] cases were excluded from the analysis. Thus a total of 204 young $(<25$ years $)$ pregnant $(<13$ weeks of gestation) women visiting the ante-natal-care facility of the PHC were recruited. At registration gestational age was determined from the self-reported date of last menstrual period (LMP) in the health care record and was confirmed using the USG reports from the PHC. The recruited women were then prospectively followed up thrice in subsequent trimesters till their delivery.

\section{Measurements}

Maternal anthropometry was measured in duplicates by the researcher using standard tools and calibrated instruments. Weight was measured using a digital weighing balance (HBF 210 Omron Corporation) to the nearest $100 \mathrm{~g}$ while the woman stood barefoot and with minimal clothing. Standing height was measured using a Seca stadiometer to the nearest $0.1 \mathrm{~cm}$ while the woman stood barefoot. The pregnant woman was asked to sit on a table with feet off the floor comfortably placed on a stool, using a Seca non-stretchable tape sitting height was measured as the distance between the vertex and the base to the nearest $0.1 \mathrm{~cm}$ while being seated. The head circumference was measured using a Seca nonstretchable tape to the nearest $0.1 \mathrm{~cm}$. The tape was placed on the widest part of the forehead and around the widest part of the back of the head while measuring. The body fat \% was measured using an analyzer HBF 210 Omron Corporation validated and used in other Indian studies $[21,22]$ as well.

Since all the deliveries took place at the PHC the birth weight $(\mathrm{g})$ and birth length $(\mathrm{cm})$ of the neonate was measured after delivery within the first $24 \mathrm{~h}$ after birth by the health care staff. A SAT B30 weighing balance was used for these measurements. The WHO definition of low birth weight (LBW) babies i.e. birth weight less than $2500 \mathrm{~g}$ and that of stunting, low length $(<45 \mathrm{~cm})$ $[23,24]$ for age was considered. All maternal and neonatal anthropometric measurements were measured in duplicates and average readings were considered for analysis.

\section{Questionnaire}

The socio-economic and demographic information was collected through a structured questionnaire redeveloped after the focus group discussions conducted by the researchers among pregnant women, community stakeholders, and family members. The questionnaire consisted of various questions to identify their socioeconomic status, demographics, and obstetric history. It was field-tested and amended after a pilot study. The questionnaire was then filled by the researcher through one-to-one interviews with the pregnant women on registration at the $\mathrm{PHC}$.

\section{Ethical approval}

The study was as per the Declaration of Helsinki and was approved by the Institutional Ethics Committee of 
Symbiosis International Deemed University. Written informed consent was obtained from participants voluntarily. Formal permissions from medical officers of PHC were also obtained before the initiation of the study in Mulshi Taluka.

\section{Statistical analysis}

The measured variables were checked for normality and expressed in terms of mean \pm standard deviation or percentages. Maternal anthropometric variables were divided into tertiles to assess the extent of change in lower and upper tertiles in association with birth weight and birth length. Means of groups were compared using a ttest and the linear trend was tested using one-way ANOVA. Logistic regression was used to estimate the risk (Odds Ratio) for LBW and stunting. The risks were also adjusted for maternal age but not for other socioeconomic variables as they were not found to be related. Analysis was performed using the statistical package for Social Sciences (SPSS) (version 20; SPSS Inc., Chicago. IL, USA). A $p$-value of $<0.05$ was considered to be significant.

\section{Results}

\section{Maternal socioeconomic status}

Most of the mothers $(77.5 \%)$ were young $(21.46 \pm 2.09$ years) at conception. $77.4 \%$ had low levels $(<10$ th standard) of school education and $42.2 \%$ were occupied as farming/laborer in addition to their household work. $42.2 \%$ of the husbands were also educated up to 10th grade and $79.9 \%$ were engaged in unskilled jobs such as driver, or owned a small shop, or worked as a clerk. A large proportion $(66.5 \%)$ of mothers were married before 20 years of age and $59.3 \%$ had delayed menarche $(<14$ years). Monthly income was low $(<10,000$ INR or $<142$ US $\$$ ) in the majority (69.1\%) of the families (Table 1).

\section{Maternal anthropometry}

Mothers were thin (mean weight $46.46 \pm 6.1 \mathrm{Kg}$ ), short (mean height $153.39 \pm 5.79 \mathrm{~cm}$ ) and undernourished (mean BMI $19.74 \pm 2.41 \mathrm{Kg} / \mathrm{m}^{2}$ ). The cut-off for maternal weight for risk of LBW is given as $38 \mathrm{Kg}$ and $5 \%$ of mothers in our study belonged to this category. Similarly, $4.4 \%$ of the mothers were shorter than risk cut-off for height $(145 \mathrm{~cm})$ and almost $33.8 \%$ of mothers were below BMI cut-off of $18.5 \mathrm{Kg} / \mathrm{m}^{2}$ indicating chronic energy deficiency. Though such risk cut-offs are not available for other anthropometric measures the Normal values have been suggested by few studies for $\mathrm{BF} \%(<$ 30\%) [25] and HC $(53 \mathrm{~cm})$ [26] and mean SHT $(74 \mathrm{~cm})$ [27] for Indian women. It can be seen that a considerable proportion of mothers have mean values below Normal for BF\%, HC, and SHT (Table 2). The neonatal
Table 1 Socioeconomic characteristics of study participants

\begin{tabular}{lll}
\hline Variable & Category & N (\%) \\
\hline Family size & $<4$ & $57(27.9)$ \\
& $4-5$ & $33(16.2)$ \\
& $>5$ & $114(55.9)$ \\
Maternal education & $<5$ th grade & $31(15.2)$ \\
& 7th grade & $39(19.1)$ \\
& 10th grade & $88(43.1)$ \\
Father's education & $>12$ th grade & $46(22.6)$ \\
& $<5$ th grade & $21(10.3)$ \\
& 7 th grade & $28(13.7)$ \\
& 10 th grade & $69(33.8)$ \\
Mathers occupation & $>12$ th grade & $86(42.2)$ \\
Maternal occupation & Laborer/farming & $86(42.2)$ \\
& Housewife & $118(57.8)$ \\
Monthly family income (US \$) & Laborer/farming & $41(20)$ \\
& Service & $163(79.9)$ \\
& $<111$ & $58(28.4)$ \\
& $111-138$ & $83(40.6)$ \\
& $>138$ & $63(30.8)$ \\
\hline
\end{tabular}

anthropometry indicated that the mean birth weight was $2655 \pm 507 \mathrm{~g}$ while the birth length was $45.38 \pm 4.1 \mathrm{~cm}$.

\section{Maternal anthropometry and prevalence of LBW}

The overall prevalence of LBW was $27.5 \%$ and that for stunting at birth was even larger viz. 38.2\%. Mean neonatal birth weight and birth length were examined by tertiles of various maternal anthropometric indicators (Table 3). Mean birth weight and length both increased significantly $(p<0.05)$ from lower tertile to higher tertile for all maternal nutritional status indicators. The difference in the mean birth weights and lengths between lowest and highest tertile of maternal weight was highest (464 g; $3.02 \mathrm{~cm}$ respectively; $p<0.001$ for both). The prevalence of LBW and that of stunting at birth were highest for mothers in the lower tertile and decreased significantly $(p<0.05$, for both) from lower to higher tertile for most indicators. It was interesting to note that the prevalence of stunting at birth was higher than that for LBW in the case of each indicator. In particular, the prevalence of stunting was significantly higher than that for LBW, for lower tertile of maternal weight (44.6 Vs $64.6 \% ; p<0.01)$ and smaller head circumference (43.7 Vs $60.6 \% ; p<0.01$ ) highlighting the importance of both current and past maternal undernutrition. Additionally, it is worthwhile to note that the prevalence of stunting at birth is over $30 \%$ even in higher tertile of maternal height as well as sitting height as both are reflective of the mother's past undernutrition (Table 3). 
Table 2 Mean $( \pm S D)$ maternal anthropometric profile

\begin{tabular}{llll}
\hline Variable & Mean( \pm SD) & $\begin{array}{l}\text { Risk cuts off } \\
\text { For LBW }\end{array}$ & Percent (\%) LBW below risk cut off \\
\hline Weight $(\mathrm{kg})$ & $46.46 \pm 6.1$ & 38 & 5 \\
Height $(\mathrm{cm})$ & $153.39 \pm 5.79$ & 145 & 4.4 \\
BMI $\left(\mathrm{kg} / \mathrm{m}^{2}\right)$ & $19.74 \pm 2.41$ & 18.5 & 33.8 \\
$\mathrm{BF}(\%)$ & $25.34 \pm 4.71$ & - & \\
HC $(\mathrm{cm})$ & $52.51 \pm 1.39$ & - & \\
SHT $(\mathrm{cm})$ & $74.64 \pm 2.8$ & - & \\
\hline
\end{tabular}

BMI Body Mass Index, BF\% Body fat \%, HC Head circumference, SHT sitting height

\section{Risk assessment}

The risk of LBW and stunting at birth by maternal nutritional status indicators was assessed using logistic regression and higher tertile as a reference category for each indicator. It can be seen that the risk for LBW was three times higher for mothers with lower tertile of weight, height, $\mathrm{BMI}, \mathrm{BF} \% \mathrm{HC}$, and $\mathrm{SHT}$. The risk of stunting at birth was larger than the risk for LBW in the case of almost all the indicators. However, it appeared more discriminatory unlike risk for LBW. It was highest (OR 7.5; CI:3.4-16.7) for lower maternal weight followed by lower BMI (OR 5.7; CI:2.6-12.3), smaller HC (OR 4.8, CI:2.3-10.3), and lower BF\% (OR 4.8; CI: 2.3-9.9).

These findings remained unchanged even after adjusting both the risks for maternal age suggesting an independent influence of maternal nutritional status on neonatal anthropometry. Thus, our observations report for the first time the effect of compromised maternal

Table 3 Mean $( \pm S D)$ neonatal measures by tertiles of maternal anthropometric indicators

\begin{tabular}{|c|c|c|c|c|c|c|}
\hline Indicators & Tertiles (value) & $\mathbf{N}$ & Birth weight(g) & Birth length (cm) & \%LBW & $\%$ Stunting \\
\hline \multirow[t]{4}{*}{ Weight (kg) } & Lower $(<42.26)$ & 65 & $2391 \pm 463$ & $43.64 \pm 3.7$ & 44.6 & 64.6 \\
\hline & Middle (42.26-48.73) & 72 & $2706 \pm 440$ & $45.77 \pm 4$ & 20.8 & 31.9 \\
\hline & Higher (> 48.73) & 67 & $2855 \pm 510$ & $46.66 \pm 4$ & 17.9 & 19.4 \\
\hline & $p$ trend & & $<0.001^{* *}$ & $<0.001^{* *}$ & $0.001^{* *}$ & $<0.001^{* *}$ \\
\hline \multirow[t]{4}{*}{ Height (cm) } & Lower $(<150.10)$ & 68 & $2506 \pm 462$ & $44.20 \pm 4$ & 34.8 & 53 \\
\hline & Middle (150.10-155.40) & 66 & $2674 \pm 521$ & $45.94 \pm 4$ & 29.4 & 29.4 \\
\hline & Higher (> 155.40) & 70 & $2777 \pm 504$ & $45.96 \pm 4.1$ & 18.6 & 32.9 \\
\hline & $p$ trend & & $0.002^{*}$ & $0.013^{*}$ & NS & $0.010^{* *}$ \\
\hline \multirow[t]{4}{*}{ BMI $\left(\mathrm{kg} / \mathrm{m}^{2}\right)$} & Lower $(<18.5)$ & 69 & $2466 \pm 415$ & $44.20 \pm 3.4$ & 39.1 & 58 \\
\hline & Middle (18.5-20.69) & 68 & $2655 \pm 518$ & $45.25 \pm 4.4$ & 26.5 & 36.8 \\
\hline & High (> 20.69) & 67 & $2849 \pm 513$ & $46.74 \pm 4.1$ & 16.4 & 19.4 \\
\hline & $p$ trend & & $<0.001^{* *}$ & $<0.001^{* *}$ & $0.012^{* *}$ & $<0.001^{* *}$ \\
\hline \multirow[t]{4}{*}{$\mathrm{BF} \%$} & Lower $(<22.73)$ & 66 & $2414 \pm 497$ & $44.07 \pm 4.1$ & 47.8 & 56.7 \\
\hline & Middle (22.73-27.86) & 67 & $2671 \pm 433$ & $45.15 \pm 4$ & 19.7 & 37.9 \\
\hline & Higher (> 27.86) & 71 & $2867 \pm 486$ & $46.83 \pm 3.8$ & 15.5 & 21.1 \\
\hline & $p$ trend & & $<0.001^{* *}$ & $<0.001^{* *}$ & $<0.001^{* *}$ & $<0.001^{* *}$ \\
\hline \multirow[t]{4}{*}{$\mathrm{SHT}(\mathrm{cm})$} & Lower $(<70)$ & 64 & $2522 \pm 529$ & $44.72 \pm 4.4$ & 42.2 & 45.3 \\
\hline & Middle (70-75.43) & 68 & $2700 \pm 525$ & $45.20 \pm 4.3$ & 23.5 & 39.7 \\
\hline & Higher (> 75.43) & 74 & $2730 \pm 450$ & $46.14 \pm 3.5$ & 18.1 & 30.6 \\
\hline & $p$ trend & & $0.018^{* *}$ & $<0.001^{* *}$ & $0.005^{* *}$ & NS \\
\hline \multirow[t]{4}{*}{$\mathrm{HC}(\mathrm{cm})$} & Lower $(<52.16)$ & 71 & $2410 \pm 421$ & $43.73 \pm 3.9$ & 43.7 & 60.6 \\
\hline & Middle (52.16-53.2) & 58 & $2719 \pm 548$ & $45.88 \pm 3.9$ & 19 & 29.3 \\
\hline & Higher (> 53.2) & 75 & $2837 \pm 517$ & $46.56 \pm 3.9$ & 18 & 24 \\
\hline & $p$ trend & & $<0.001^{* *}$ & $<0.001^{* *}$ & $0.001^{* *}$ & $<0.001^{* *}$ \\
\hline
\end{tabular}

One way ANOVA; *p value $<0.05 ; * * p$ value $<0.01$ 
nutritional status on the risk of stunting at birth in addition to the risk of LBW. Additionally, our findings highlight the importance of the mother's past undernutrition as reflected by smaller $\mathrm{HC}$ and short height and sitting height in addition to current undernutrition (Table 4).

\section{Discussion}

Maternal nutritional status has been considered to be the most important factor influencing birth outcomes. LBW due to poor pre-pregnancy weight $[28,29]$, poor gestational weight gain $[8,28]$, short stature $[13,30]$ and poor arm circumferences $[13,31]$ have been studied globally. Maternal HC and SHT are of prominence as they reflect the past nutritional status of the mother. About stunting at birth and associated maternal factors there is hardly any research evidence documented. We observed that apart from the current undernutrition, maternal past undernutrition reflected by smaller $\mathrm{HC}$, shorter height, and shorter sitting height also confer risk for both LBW and stunting at birth. The risk is doubled for stunting at birth than LBW significantly for the lower maternal weight $(<42.26 \mathrm{~kg})$ and smaller $\mathrm{HC}(<52.16$ $\mathrm{cm}$ ) which often is unnoticed.

The mothers in our study were overtly undernourished with poor maternal anthropometry. 33.5\% of mothers were chronically undernourished (BMI <
$18.5 \mathrm{~kg} / \mathrm{m}^{2)}$. These observations are similar to those reported by Raje et al., 2015 [32] among rural women from Maharashtra. Poor maternal BMI is known to be one of the major risk factors for poor birth outcomes. In our study too, the mean birth weight was low $(2655 \pm 507 \mathrm{~g})$, with the shorter birth length.

$(45.38 \pm 4.1 \mathrm{~cm})$. The prevalence of LBW was $27.5 \%$ which was similar to that reported for South Asia (UNICEF global database 2014) and was closer (24.7\%) to the region-specific western rural populations of India [33]. The prevalence of stunting at birth was even higher (38.2\%) than that for LBW but none of the Indian studies have previously reported.

Several studies have reported a positive correlation between maternal anthropometry and mean birth weights in different populations [34-36]. India's poor fetal growth is at least partly caused by a maternal chronic energy deficiency and stunting [37-39]. Both mean birth weight and length at birth increased as maternal nutritional status improved from lower tertile to higher tertile for each indicator. Differences observed in mean birth weight for babies of mothers in the lower and higher tertile were similar to those reported from a study in rural areas of Maharashtra [21]. However, there aren't any studies reporting the association of maternal $\mathrm{HC}$ with that of stunting at birth.

Table 4 Risk of LBW and stunting at birth by maternal anthropometric indicators

\begin{tabular}{|c|c|c|c|c|c|}
\hline \multirow[t]{2}{*}{ Indicators } & \multirow[t]{2}{*}{ Tertile } & \multicolumn{2}{|c|}{ OR $(95 \% \mathrm{CI})$ for LBW } & \multicolumn{2}{|c|}{ OR $(95 \% \mathrm{Cl})$ for Stunting } \\
\hline & & Unadjusted & Adjusted $^{+}$ & Unadjusted & Adjusted $^{+}$ \\
\hline \multirow[t]{3}{*}{ Weight (kg) } & $>48.73$ & 1 & 1 & 1 & 1 \\
\hline & $42.26-48.73$ & $1.2(0.5-2.8)$ & $1.1(0.4-2.7)$ & $1.9(0.8-4.2)$ & $1.8(0.8-4)$ \\
\hline & $<42.26$ & $3.6(1.6-8.1) * *$ & $3.5(1.5-7.9)^{*}$ & $7.5(3.4-16.7)^{* *}$ & $6.8(3-15.2)^{* *}$ \\
\hline \multirow[t]{3}{*}{ Height (cm) } & $>155.40$ & 1 & 1 & 1 & 1 \\
\hline & $150.10-55.40$ & $1.8(0.8-4.0)$ & $1.8(0.8-4.1)$ & $0.8(0.4-1.7)$ & $0.8(0.4-1.7)$ \\
\hline & $<150.10$ & $2.3(1-5.1)^{*}$ & $2.3(1-5.1)^{*}$ & $2.3(1.1-4.6)^{* *}$ & $2.2(1.1-4.6)^{*}$ \\
\hline \multirow[t]{3}{*}{ BMI (kg/m2) } & $>20.69$ & 1 & 1 & 1 & 1 \\
\hline & $18.5-20.69$ & $1.8(0.7-4.2)$ & $1.7(0.7-4.1)$ & $2.4(1.1-5.2)$ & $2.2(1-5)^{*}$ \\
\hline & $<18.5$ & $3.2(1.4-7.3) *$ & $3.1(1.3-7)^{* *}$ & $5.7(2.6-12.3)^{*}$ & $5.1(2.3-11.3)^{* *}$ \\
\hline \multirow[t]{3}{*}{$\mathrm{BF} \%$} & $>27.86$ & 1 & 1 & 1 & 1 \\
\hline & $22.73-27.86$ & $1.3(0.5-3.2)$ & $1.2(0.5-3.1)$ & $2.2(1-4.8)^{*}$ & $2(0.9-4.3)$ \\
\hline & $<22.73$ & $4.9(2.2-11.1) * *$ & $4.7(2.1-10.9)^{* *}$ & $4.8(2.3-10.3)^{*}$ & $4.3(2-9.2)^{* *}$ \\
\hline \multirow[t]{3}{*}{$\mathrm{SHT}(\mathrm{cm})$} & $>75.43$ & 1 & 1 & 1 & 1 \\
\hline & $70-75.43$ & $1.3(0.6-3.1)$ & $1.3(0.5-3)$ & $1.4(0.7-3.0)$ & $1.4(0.7-2.8)$ \\
\hline & $<70$ & $3.3(1.5-7.2)^{*}$ & $3.2(1.4-7)^{* *}$ & $1.8(0.9-3.8)^{*}$ & $1.7(0.8-3.5)$ \\
\hline \multirow[t]{3}{*}{$\mathrm{HC}(\mathrm{cm})$} & $>53.2$ & 1 & 1 & 1 & 1 \\
\hline & $52.16-53.2$ & $1.0(0.4-2.4)$ & $0.9(0.3-2.3)$ & $1.3(0.6-2.8)$ & $1.1(0.5-2.5)$ \\
\hline & $<52.16$ & $3.3(1.6-7.1)^{* *}$ & $3.1(1.4-6.7)^{* *}$ & $4.8(2.3-9.9)^{* *}$ & $4.4(2.1-9.1)^{* *}$ \\
\hline
\end{tabular}

Odds ratio; ${ }^{*} p$ value $<0.05 ; * *$ value $<0.01 ;{ }^{+}$Adjusted for maternal age 
The highest prevalence of stunting at birth was observed in the lower tertile of maternal weight, the indicator of current undernutrition, as well as among mothers in the lowest tertile of $\mathrm{HC}$, the indicator of maternal undernutrition in utero. These observations highlight the enormous intergenerational impact of compromised maternal nutritional status more on stunting at birth than that of LBW and hence deserves further attention.

Although, the factors associated with the birth outcome are well studied those associated with risk of LBW or stunting at birth are not $[40,41]$. Identifying nutritional factors associated with these risks are of critical importance as achievement in reduction of prevalence will have multifactorial benefits such as reduction in mortality and morbidity, and improving the growth rate of children, etc. We observed that the risk for LBW was three times higher for mothers in the lower tertiles for Wt, Ht, BMI, BF, HC, and SHT compared to those in the higher tertile. Similar risks are reported for women from Ethiopia [42], Pakistan [43], and Maharashtra [44]. However, these studies examined risk cut-offs for height, weight, and BMI but not for SHT and HC. In the event of scarce data, it may be noted that our observations offer risk cut-offs for maternal SHT $(70 \mathrm{~cm})$ and HC (52 $\mathrm{cm}$ ) for early detection of the risk of LBW and stunting at birth.

Although maternal nutritional status indicators such as shorter sitting height, smaller head circumference have shown to be associated with LBW [ 12], their association with stunting at birth has not been explored. We observed that the risk of stunting at birth was much higher than that for LBW, especially in the case of maternal weight $(\mathrm{OR}=7.5$; $\mathrm{CI}$ : 3.4-16.7), $\mathrm{BMI}(\mathrm{OR}=5.7$; CI: 2.6-12.3), and $\mathrm{HC}(\mathrm{OR}=4.8 ; \mathrm{CI}: 2.3-9.9)$. It is worthwhile to note that the risks remained significant even after adjusting for maternal age indicating an independent influence of compromised maternal nutritional status.

We would like to mention some of the limitations. Firstly, the study does not address other factors such as physical activity and diet which are also known to affect the birth outcome. Because all women came from farming families with similar socio-economic backgrounds it is unlikely to affect the associations of maternal anthropometry with birth outcome observed in this study. Maternal diet being a major avenue will be dealt with in another communication and cannot be accommodated in the same paper. Other factors such as substance abuse are not culturally acceptable and hence have not been considered.

\section{Conclusion}

The observation in this study that smaller SHT, like smaller maternal $\mathrm{HC}$, seems to be a surrogate measure of maternal undernutrition in utero and deserves attention considering the Barker hypothesis for risk of metabolic diseases in later life $[45,46]$. The possible physiological explanation appears to be that maternal undernutrition prioritizes the blood flow towards the protection of vital organs such as the brain and heart situated in the upper part of the body affecting skeletal growth of epiphysis [47] probably resulting in a shorter sitting height. The intergenerational influence of smaller maternal size is documented by Ramakrishnan U et.al, 1999 [48] in the Guatemalan birth cohort. Future studies can be conducted and validated in similar settings of other developing countries in South East Asia.

\section{Abbreviations \\ LBW: Low Birth Weight; OR: Odds ratio; AOR: Adjusted Odds Ratio; $\mathrm{Cl}$ : Confidence Interval; SPSS: Statistical Package for Social Sciences}

\section{Acknowledgments}

We would like to thank all the participants of the study. The medical officers of the primary health center and health workers were helpful in the conduct of the study. Additionally, we would like to thank the institutional authorities at Symbiosis School of Biological Sciences, Symbiosis community outreach, and extension (SCOPE), Symbiosis International (Deemed University). We would like to declare that there are no conflicts of interest associated with this manuscript.

\section{Authors' contributions}

DG conceived and designed the study, performed the analysis and interpretation of the data. SR guided for design, conception, analysis, and interpretation of data. Both authors read and approved the final manuscript.

\section{Funding}

None.

Availability of data and materials

The datasets used and analyzed for the present study will be available from the corresponding author on reasonable request.

\section{Declarations}

Ethics approval and consent to participate

This clearance was obtained from Symbiosis International Deemed University's independent ethics committee and permission was also obtained from the medical officer of the primary health center of each area. Informed written consents were obtained from study participants and the study objectives were explained to them. Those who volunteered to participate were not enforced to respond. The confidentiality of the collected information was ensured at all levels.

\section{Consent for publication}

Not applicable.

\section{Competing interests}

The authors declare that no competing interests.

\section{Author details}

${ }^{1}$ Symbiosis Institute of Health Sciences, Symbiosis International Deemed University, Pune, Maharashtra 412115, India. ${ }^{2}$ Society for Initiatives in Nutrition and Development, Pune, Maharashtra 411007, India.

Received: 7 February 2021 Accepted: 6 October 2021

Published online: 17 November 2021

\section{References}

1. Dalal A, Chauhan S, Bala DV. Epidemiological determinants of low birth weight in Ahmedabad city: a facility based case-control study. Int J Med Sci 
Public Health. 2014;3(4):430-2. https://doi.org/10.5455/ijmsph.2014.26012 0144.

2. Wilcox AJ. On the importance - and the unimportance —of birthweight. Int J Epidemiol. 2001;30(6):1233-41. https://doi.org/10.1093/ije/30.6.1233.

3. Devaki G, Shobha R. Maternal anthropometry and low birth weight: a review. Biomed Pharmacol J. 2018;11(2):815-20. https://doi.org/10.13005/ $\mathrm{bpj} / 1436$.

4. Kibret KT, Chojenta C, Gresham E, Tegegne TK, Loxton D. Maternal dietary patterns and risk of adverse pregnancy (hypertensive disorders of pregnancy and gestational diabetes mellitus) and birth (preterm birth and low birth weight) outcomes: a systematic review and meta-analysis. Public Health Nutr. 2019;22(3):506-20. https://doi.org/10.1017/S1368980018002616.

5. Swaminathan S, Hemalatha R, Pandey A, Kassebaum NJ, Laxmaiah A, Longvah $\mathrm{T}$, et al. The burden of child and maternal malnutrition and trends in its indicators in the states of India: the global burden of disease study 1990-2017. Lancet Child Adolesc Health. 2019;3(12):855-70. https://doi.org/1 0.1016/S2352-4642(19)30273-1.

6. Papathakis PC, Singh LN, Manary MJ. How maternal malnutrition affects linear growth and development in the offspring. Mol Cell Endocrinol. 2016; 435:40-7. https://doi.org/10.1016/j.mce.2016.01.024.

7. Kramer MS. Maternal nutrition, pregnancy outcome and public health policy. Cmaj. 1998;159(6):663-5.

8. Zhao R, Xu L, Wu ML, Huang SH, Cao XJ. Maternal pre-pregnancy body mass index, gestational weight gain influence birth weight. Women and Birth. 2018;31(1):e20-5. https://doi.org/10.1016/j.wombi.2017.06.003.

9. Ojha N, Malla DS. Low birth weight at term: relationship with maternal anthropometry. JNMA; J Nepal Med Assoc. 2007;46(166):52-6.

10. Yadav DK, Shukla GS, Gupta N, Shrestha N, Singh A, Kaphle HP. Maternal and obstetric factors associated with low birth weight. J Nepal Health Res Counc. 2019;17(4):443-50. https://doi.org/10.33314/jnhrc.v17i4.2263.

11. Pomeroy E, Wells JC, Cole TJ, O'Callaghan M, Stock JT. Relationships of maternal and paternal anthropometry with neonatal body size, proportions and adiposity in an Australian cohort. Am J Phys Anthropol. 2015;156(4): 625-36. https://doi.org/10.1002/ajpa.22680.

12. Yajnik CS, Fall CH, Coyaji KJ, Hirve SS, Rao S, Barker DJ, et al. Neonatal anthropometry: the thin-fat Indian baby. The Pune maternal nutrition study. Int J Obes. 2003;27(2):173-80. https://doi.org/10.1038/sj.ijo.802219.

13. Nahar S, Mascie-Taylor CG, Begum HA. Maternal anthropometry as a predictor of birth weight. Public Health Nutr. 2007;10(9):965-70. https://doi. org/10.1017/S1368980007217975

14. Shakya KL, Shrestha N, Kisiju P, Onta SR. Association of maternal factors with low birth weight in selected hospitals of Nepal. J Nepal Health Res Counc. 2015;13(30):121-125

15. He Z, Bishwajit G, Yaya S, Cheng Z, Zou D, Zhou Y. Prevalence of low birth weight and its association with maternal body weight status in selected countries in Africa: a cross-sectional study. BMJ Open. 2018;8(8):e020410. https://doi.org/10.1136/bmjopen-2017-020410.

16. Gondwe A, Ashorn P, Ashorn U, Dewey KG, Maleta K, Nkhoma M, et al. Prepregnancy body mass index (BMI) and maternal gestational weight gain are positively associated with birth outcomes in rural Malawi. PLoS One. 2018; 13(10):e0206035. https://doi.org/10.1371/journal.pone.0206035.

17. Moreira A, Sousa P, Sarno F. Low birth weight and its associated factors. Einstein (Sao Paulo, Brazil). 2018;16(4):eAO4251. https://doi.org/10.31744/ einstein_journal/2018AO4251.

18. Coall DA, Chisholm JS. Evolutionary perspectives on pregnancy: maternal age at menarche and infant birth weight. Soc Sci Med (1982). 2003;57(10): 1771-81. https://doi.org/10.1016/50277-9536(03)00022-4.

19. Kaur S, Ng CM, Badon SE, Jalil RA, Maykanathan D, Yim HS, et al. Risk factors for low birth weight among rural and urban Malaysian women. BMC Public Health. 2019;19(4):539. https://doi.org/10.1186/s12889-019-6864-4.

20. Winder NR, Krishnaveni GV, Veena SR, Hill JC, Karat CL, Thornburg KL, et al. Mother's lifetime nutrition and the size, shape and efficiency of the placenta. Placenta. 2011;32(11):806-10. https://doi.org/10.1016/j.placenta.2 011.09.001.

21. Rao S, Raje S. Nutritional risk factors of low birth weight among poor rural mothers from Maharashtra, India. J Nutr Health Food Sci. 2017:5(4): $1-7$.

22. Deshpande-Joshi SS, Rao S. Differential risk of hypertension among lean and nonlean rural subjects in relation to decadal changes in anthropometry. J Am Coll Nutr. 2018;37(5):380-6. https://doi.org/10.1080/07315724.2017.14 05750.
23. WHO cut offs: https://www.who.int/tools/child-growth-standards/standards/ weight-for-length-height

24. De Onis M, Dewey KG, Borghi E, Onyango AW, Blössner M, Daelmans B, et al. The World Health Organization's global target for reducing childhood stunting by 2025: rationale and proposed actions. Matern Child Nutr. 2013;9:6-26.

25. Dudeja V, Misra A, Pandey RM, Devina G, Kumar G, Vikram NK. BMl does not accurately predict overweight in Asian Indians in northern India. Br J Nutr. 2001 Jul;86(1):105-12. https://doi.org/10.1079/BJN2001382.

26. Head circumference WHO: https://cdn.who.int/media/docs/default-source/ child-growth/child-growth-standards/indicators/head-circumference-for-age/ girls-chart\%2D\%2Dhead-circumference-for-age\%2D\%2D-birth-to-5-years(percentile).pdf?sfvrsn=6468c3a2_2

27. Banik SD. Sitting height ratio and interpretation of BMI-based nutritional status among Sarak adults of Bundu, Ranchi, Jharkhand. India Anthropol Notebooks. 2016;22(1)

28. Kumar SG, Kumar HH, Jayaram S, Kotian MS. Determinants of low birth weight: a case control study in a district hospital in Karnataka. Indian J Pediatr. 2010;77(1):87-9. https://doi.org/10.1007/s12098-009-0269-9.

29. Shivakumar N, Dwarkanath P, Bosch R, Duggan C, Kurpad AV, Thomas T. Influence of gestational weight gain on low birth weight in short-statured south Indian pregnant women. Eur J Clin Nutr. 2018;72(5):752-60. https:// doi.org/10.1038/s41430-017-0027-4.

30. Sebayang SK, Dibley MJ, Kelly PJ, Shankar AV, Shankar AH, SUMMIT Study Group. Determinants of low birthweight, small-for-gestational-age and preterm birth in Lombok, Indonesia: analyses of the birthweight cohort of the SUMMIT trial. Tropical Med Int Health. 2012;17(8):938-50. https://doi. org/10.1111/j.1365-3156.2012.03039.x.

31. Janjua NZ, Delzell E, Larson RR, Meleth S, Kristensen S, Kabagambe E, et al. Determinants of low birth weight in urban Pakistan. Public Health Nutr. 2009;12(6):789-98. https://doi.org/10.1017/S1368980008002942.

32. Raje S, Rao S. Maternal food consumption patterns and risk of low birth weight in rural Maharashtra. Indian J Nutr Diet. 2015;52(2).

33. Dubey DK, Nath DC. Regional models assessing region-specific determinants of low birth weight in India. Curr Sci. 2019;116(10):1674. https://doi.org/10.18520/cs/v116/i10/1674-1682.

34. Godfrey K, Robinson S, Barker DJ, Osmond C, Cox V. Maternal nutrition in early and late pregnancy in relation to placental and fetal growth. BMJ. 1996:312(7028):410-4. https://doi.org/10.1136/bmj.312.7028.410.

35. Padonou SG, Aguemon B, Bognon GM, Houessou NE, Damien G, Ayelo P, et al. Poor maternal anthropometric characteristics and newborns' birth weight and length: a cross-sectional study in Benin. Int Health. 2019;11(1): 71-7. https://doi.org/10.1093/inthealth/ihy056.

36. Abubakari A, Kynast-Wolf G, Jahn A. Maternal determinants of birth weight in northern Ghana. PLoS One. 2015;10(8):e0135641. https://doi.org/10.1371/ journal.pone.0135641.

37. Gopalan C. LBWs: Significance and implications. In: Sachdev HPS, Choudhary $P$, editors. Nutrition in children: developing country concerns. Imprint; New Delhi: 1994. pp. 1-33.

38. Purushothaman V, Kupputhai U, Meenakshi ND. Nutritional profile of selected expectant mothers and the cost of pregnancy. Indian J Nutr Diet. 1988;25(8):247-53.

39. Fall CHD. Fetal Malnutrition and Long-Term Outcomes. In: Bhatia J, Bhutta ZA, Kalhan SC (eds): Maternal and Child Nutrition: The First 1,000 Days. Nestlé Nutr Inst Workshop Ser. Nestec Ltd. Vevey/S. Karger AG Basel, 2013, vol 74, pp 11-25. https://doi.org/10.1159/000348384.

40. Bang AT, Bang RA, Baitule S, Deshmukh M, Reddy MH. Burden of morbidities and the unmet need for health care in rural neonates-a prospective observational study in Gadchiroli. India Indian Pediatr. 2001; 38(9):952-66.

41. Niswade A, Zodpey SP, Ughade S, Bangdiwala SI. Neonatal morbidity and mortality in tribal and rural communities in Central India. Indian J Community Med. 2011;36(2):150-8. https://doi.org/10.4103/0970-0218.84137.

42. Demelash H, Motbainor A, Nigatu D, Gashaw K, Melese A. Risk factors for low birth weight in bale zone hospitals, south-East Ethiopia: a case-control study. BMC Pregnancy Childbirth. 2015;15(1):264. https://doi.org/10.1186/s12 884-015-0677-y.

43. Gul R, Iqbal S, Anwar Z, Ahdi SG, Ali SH, Pirzada S. Pre-pregnancy maternal BMl as predictor of neonatal birth weight. PLoS One. 2020;15(10):e0240748. https://doi.org/10.1371/journal.pone.0240748.

44. Mumbare SS, Maindarkar G, Darade R, Yenge S, Tolani MK, Patole K. Maternal risk factors associated with term low birth weight neonates: a 
matched-pair case control study. Indian Pediatr. 2012;49(1):25-8. https://doi. org/10.1007/s13312-012-0010-z.

45. De Boo HA, Harding JE. The developmental origins of adult disease (Barker) hypothesis. Aust N Z J Obstet Gynaecol. 2006;46(1):4-14. https://doi.org/1 0.1111/j.1479-828X.2006.00506.X.

46. Starr MC, Hingorani SR. Prematurity and future kidney health: the growing risk of chronic kidney disease. Curr Opin Pediatr. 2018;30(2):228-35. https:// doi.org/10.1097/MOP.0000000000000607.

47. Bogin B, Varela-Silva MI. Leg length, body proportion, and health: a review with a note on beauty. Int J Environ Res Public Health. 2010;7(3):1047-75. https://doi.org/10.3390/ijerph7031047.

48. Ramakrishnan U, Martorell R, Schroeder DG, Flores R. Role of intergenerational effects on linear growth. J Nutr. 1999;129(2):544S-9S, https://doi.org/10.1093/jn/129.2.544S.

\section{Publisher's Note}

Springer Nature remains neutral with regard to jurisdictional claims in published maps and institutional affiliations.

Ready to submit your research? Choose BMC and benefit from:

- fast, convenient online submission

- thorough peer review by experienced researchers in your field

- rapid publication on acceptance

- support for research data, including large and complex data types

- gold Open Access which fosters wider collaboration and increased citations

- maximum visibility for your research: over $100 \mathrm{M}$ website views per year

At BMC, research is always in progress.

Learn more biomedcentral.com/submissions 